18,12

\title{
Двумерная модель рулонных упаковок молекулярных нанолент
}

\author{
(C) A.B. Савин ${ }^{1,2}$, M.A. Мазо ${ }^{1}$ \\ ${ }^{1}$ Институт химической фризики им. Н.Н. Семенова РАН, \\ Москва, Россия \\ ${ }^{2}$ Российский экономический университет им. Г.В. Плеханова, \\ Москва, Россия \\ E-mail: asavin@center.chph.ras.ru
}

(Поступила в Редакцию 7 ноября 2017 г.)

\begin{abstract}
Предложена упрощенная модель молекулярной цепи на плоскости, позволяющая описать складчатые и рулонные упаковки молекулярных нанолент различной структуры. С использованием данной модели получены возможные стационарные состояния рулонов однослойных нанолент графена, графана, фторографена и фторографана (гидрированного с одной стороны и фторированного с другой стороны графена). Показана их устойчивость и рассчитана энергия как функция длины наноленты. Показано, что при больших длинах рулонная упаковка является наиболее энергетически выгодной конформацией наноленты. Для нанолент фторографена впервые показана возможность существования рулонных упаковок, а для нанолент фторографана - существование двух разных типов рулонов, которые в цепной модели соответствуют левым и правым спиралям Архимеда. Простота предложенной модели позволяет рассматривать динамику рулонов молекулярных нанолент достаточно большой длины и на достаточно больших интервалах времени.
\end{abstract}

Исследование выполнено при финансовой поддержке Российского научного фонда (проект 16-13-10302). Вычислительные ресурсы предоставлены межведомственным суперкомпьютерным центром РАН.

DOI: $10.21883 /$ FTT.2018.04.45700.318

\section{1. Введение}

В последнее время проводятся интенсивные исследования графена в различных конформациях, что вызвано его уникальными электрическими и механическими свойствами [1-5]. Графен является двумерной структурой, имеющей рекордные жесткость и прочность на разрыв, но легко изгибающейся в пространстве. В особый класс углеродных наноматериалов можно отнести вторичные структуры (складки, рулоны), устойчивость которых обеспечивают слабые невалентные (ван-дерваальсовы) взаимодействия атомов углерода. Еще в 1960 г. было обнаружено, что при использовании графитовой смазки из плоских кусков графита образуются микроскопические рулоны, играющие роль роликовых подшипников и обеспечивающих низкое значение коэффициента трения [6]. Нанолента графена, сворачиваясь в рулон, образует новую квазиодномерную структуру, имеющую в поперечном сечении форму усеченной спирали Архимеда. Геометрическая форма рулона определяется балансом выигрыша энергии за счет увеличения числа ван-дер-ваальсовых связей между соприкасающимися участками листа графена и потери энергии на изгиб наноленты.

Имеется несколько экспериментальных технологий получения рулонов нанолент графена и изучения их структуры и свойств [7-12]. Свойства рулонной упаковки углеродных нанолент изучались в серии теоретических работ. Электрические, оптические и механи- ческие свойства рулонов коротких нанолент моделировались из первых принципов [13-15]. Механические свойства рулонов из более длинных нанолент и различные сценарии их самосборки описаны с использованием метода молекулярной динамики в работах [1626]. Механические свойства рулонов длинных нанолент были описаны в рамках континуальной модели упругого стержня свернутого в спираль $[16,21,27,28]$, в которой энергия изгиба стержня компенсируется энергетическим выигрышем от взаимодействия соприкасающихся стенок.

При моделировании динамики складок и рулонов нанолент всегда использовались полноатомные модели. Такие модели требуют значительных компьютерных ресурсов и не позволяют рассматривать динамику длинных нанолент на значительных отрезках времени. Поэтому обычно рассматриваются рулоны, имеющие только два или три витка. Сложность полноатомных моделей также затрудняет проведение полного анализа возможных стационарных упаковок длинных нанолент. Для преодоления этих трудностей в работах $[29,30]$ была предложена двумерная модель молекулярной цепи позволяющая с высокой точностью описать возможные стационарные состояния рулонных упаковок нанолент графена. В данной работе будет предложена более упрощенная модель двумерной цепи позволяющая описывать стационарные состояния рулонных упаковок молекулярных нанолент различной химической структуры. С использованием 
модели будут получены возможные стационарные состояния рулонов однослойных нанолент графена, графана, фторографена и фторографана. Модель может быть применена как для описания рулонных упаковок молекулярных нанолент с одинаковыми поверхностями (нанолент нитрида бора, силицина, фосфорена, карбоннитрида, и т.д.), так и для нанолент, стороны которых имеют разную химическую модификацию (наноленты графона и их аналоги).

\section{2. Цепная модель молекулярной наноленты}

Молекулярная нанолента представляет собой полосу постоянной ширины, вырезанную из однослойной молекулярной плоскости. Простейшим примером такой молекулярной плоскости является лист графена (изолированный монослой атомов углерода кристаллического
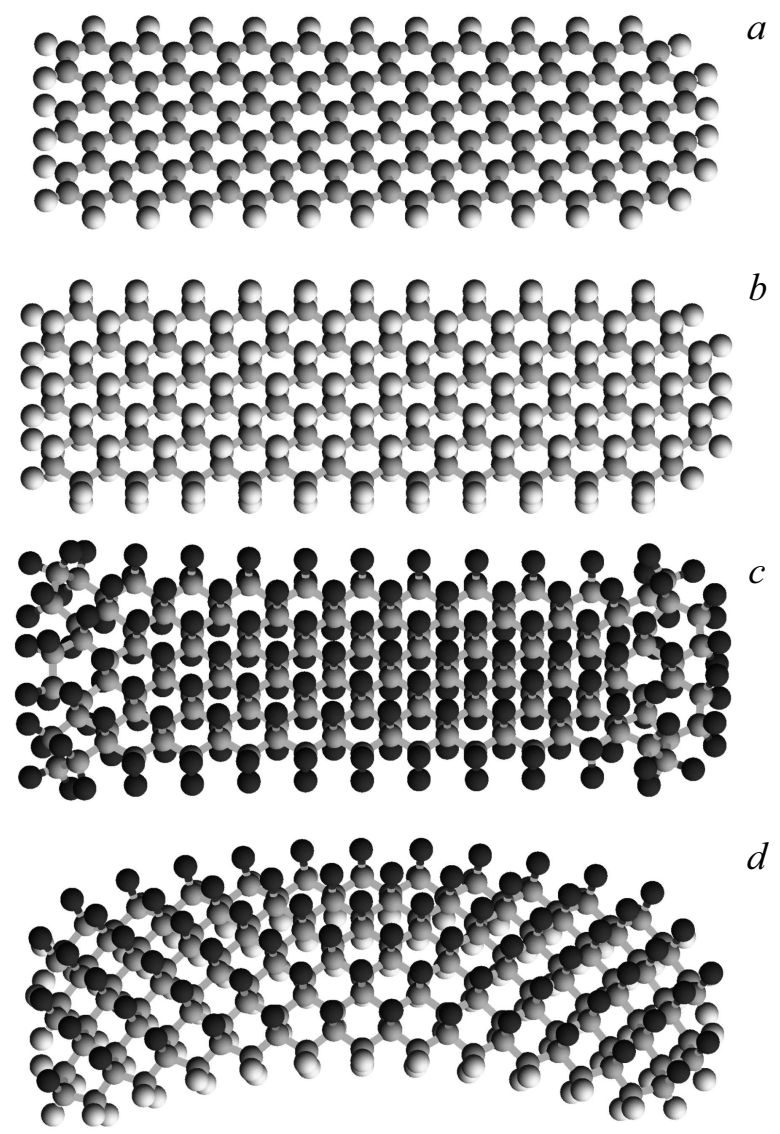

Pис. 1. Структуры $(a)$ наноленты графена $\left(\mathrm{C}_{12} \mathrm{H}_{2}\right)_{11} \mathrm{C}_{10} \mathrm{H}_{12} \quad$ (размер $\left.2.985 \times 1.344 \mathrm{~nm}\right) ; \quad(b)$ наноленты графана $\left(\mathrm{C}_{12} \mathrm{H}_{14}\right)_{11} \mathrm{C}_{10} \mathrm{H}_{22} \quad$ (размер $3.094 \times 1.280 \mathrm{~nm}$ ); (c) наноленты фторографена (фторированного графена) $\left(\mathrm{C}_{12} \mathrm{~F}_{14}\right){ }_{11} \mathrm{C}_{10} \mathrm{~F}_{22}$ (размер $\left.3.024 \times 1.349 \mathrm{~nm}\right) ;(d)$ фторографана $\left(\mathrm{C}_{12} \mathrm{H}_{8} \mathrm{~F}_{6}\right)_{11} \mathrm{C}_{10} \mathrm{H}_{15} \mathrm{~F}_{5}$ (гидрированного с одной стороны и фторированного с другой стороны графена). Атомы водорода показаны светлыми, углерода - серыми, а фтора - более темными шариками.

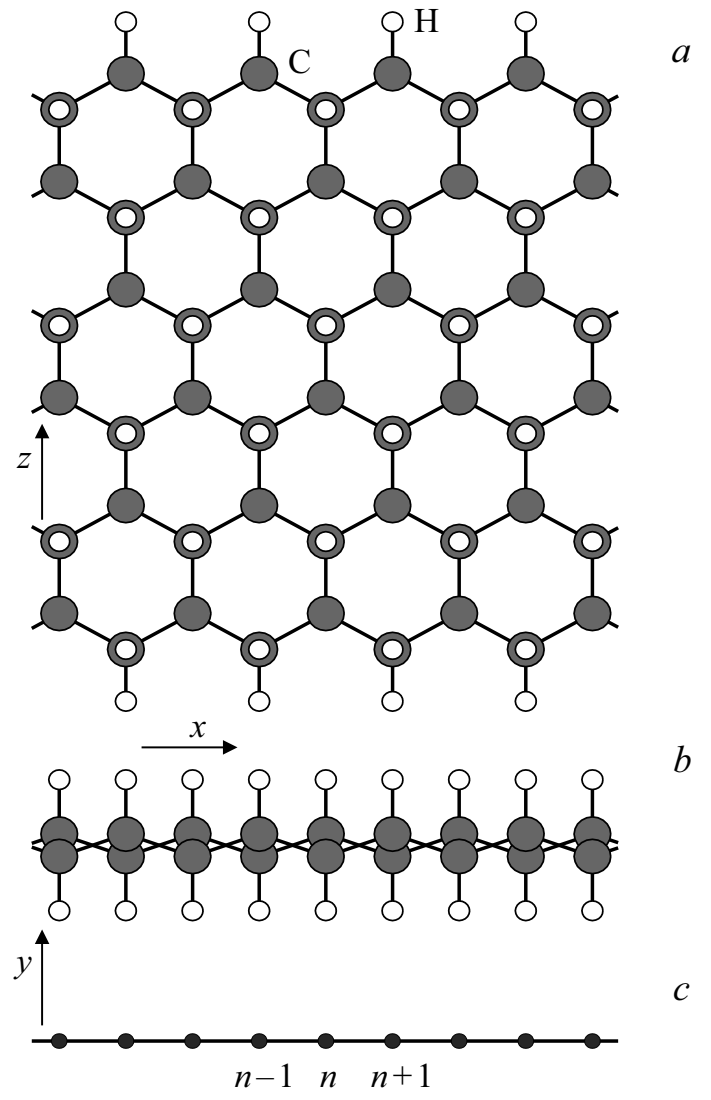

Рис. 2. Вид сверху $(a)$ и сбоку $(b)$ на наноленту графана $\left(\mathrm{C}_{12} \mathrm{H}_{14}\right)_{\infty}$ со структурой зигзаг (нанолента лежит в плоскости $x z),(c)$ модель цепи частиц на плоскости $x y$, в которой частица задает положение соответствующей поперечной линии атомов наноленты $(n-$ номер линии).

графита) и его различные химические модификации: графан (гидрированный с двух сторон лист графена), фторографен (фторированный графен), фторографан (гидрированный с одной стороны и фторированный с другой стороны лист графена) (рис. $1, a-d)$. Как известно, графен и его модификации являются упруго изотропными материалами, продольная и изгибная жесткость которых слабо зависит от хиральности структуры. Поэтому мы для определенности будем рассматривать наноленты со структурой зигзаг, представленные на рис. 1.

Пусть в основном состоянии нанолента лежит в плоскости $x z$ трехмерного пространства вдоль оси $x$ (рис. 2,a). Такая нанолента является периодической структурой с постоянным шагом. Трансляционные ячейки этой структуры образуют атомы, расположенные вдоль линий параллельных оси $z$ (вдоль поперечных линий). Рассмотрим такие движения наноленты, при которых ее атомы, расположенные на линиях параллельных оси $z$, перемещаются как жесткое целое в плоскости $x y$, сохраняя свои координаты по оси $z$. Тогда эти атомные линии можно рассмотреть как эффективные частицы, двигающиеся в плоскости $x y$, а движение 


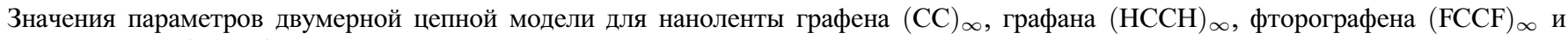
фторографана $(\mathrm{HCCF})_{\infty}$

\begin{tabular}{c|c|c|c|c|c|c|c|c|c}
\hline Нанолента & $M\left(m_{p}\right)$ & $R_{0}(\mathrm{~nm})$ & $K(\mathrm{~N} / \mathrm{m})$ & $\epsilon(\mathrm{eV})$ & $\theta_{0}(\mathrm{deg})$ & $\epsilon_{0}(\mathrm{eV})$ & $r_{0}(\mathrm{~nm})$ & $k$ & $l$ \\
\hline $\mathrm{CC}$ & 24 & 0.1228 & 910.0 & 7.00 & 180 & 0.01970 & 0.368 & 8 & 5 \\
$\mathrm{HCCH}$ & 26 & 0.1261 & 607.2 & 3.38 & 180 & 0.00984 & 0.501 & 16 & 6 \\
$\mathrm{FCCF}$ & 62 & 0.1285 & 606.6 & 4.00 & 180 & 0.00304 & 0.575 & 20 & 9 \\
$\mathrm{HCCF}$ & 44 & 0.1285 & 607.0 & 3.70 & 177 & 0.00325 & 0.506 & 16 & 3
\end{tabular}

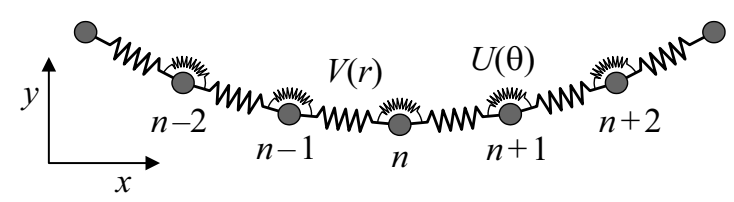

Рис. 3. Механическая модель цепи частиц на плоскости $x y$, описывающая продольную и изгибную подвижность наноленты. Потенциал $V(r)$ описывает продольную жесткость, а угловой потенциал $U(\theta)$ - изгибную жесткость цепи.

наноленты сведется к движению цепи из этих частиц (рис. 2, $b, c)$.

Таким образом, продольные и изгибные движения наноленты могут быть описаны как движения цепи частиц в плоскости $x y$. Простейшая модель молекулярной цепи в двухмерном пространстве представлена на рис. 3. Гамильтониан цепи имеет вид

$$
\begin{aligned}
H= & \sum_{n=1}^{N} \frac{1}{2} M\left(\dot{x}_{n}^{2}+\dot{y}_{n}^{2}\right)+\sum_{n=1}^{N-1} V\left(R_{n}\right) \\
& +\sum_{n=2}^{N-1} U\left(\theta_{n}\right)+\sum_{n=1}^{N-3} \sum_{k=n+3}^{N} W\left(r_{n k}\right),
\end{aligned}
$$

где $N$ - число частиц в цепи, $M$ - масса частицы, а вектор $\mathbf{u}_{n}=\left(x_{n}, y_{n}\right)$ задает положение $n$-ой частицы.

Потенциал

$$
V(R)=K\left(R-R_{0}\right)^{2} / 2,
$$

отвечает за продольную жесткость цепи, $K-$ жесткость взаимодействия, $R_{0}-$ равновесная длина связи (шаг цепи), $R_{n}=\left|\mathbf{u}_{n+1}-\mathbf{u}_{n}\right|-$ расстояние между соседними частицами $n$ и $n+1$.

Потенциал

$$
U(\theta)=\epsilon\left[1-\cos \left(\theta-\theta_{0}\right)\right] \approx \epsilon\left(\theta-\theta_{0}\right)^{2} / 2,
$$

описывает изгибную подвижность цепи, $\theta-$ валентный угол, образованный двумя соседними связями, $\theta_{0}-$ равновесное значение угла, параметр $\epsilon>0$ задает изгибную жесткость цепи. Для $n$-го валентного угла $\cos \left(\theta_{n}\right)=-\left(\mathbf{u}_{n-1}, \mathbf{u}_{n}\right) /\left|\mathbf{u}_{n-1}\right| \cdot\left|\mathbf{u}_{n}\right|$.

Потенциал Леннарда-Джонса $(l, k)$

$$
W(r)=\varepsilon\left[l\left(r_{0} / r\right)^{k}-k\left(r_{0} / r\right)^{l}\right] /(k-l),
$$

описывает слабое невалентное взаимодействие удаленных узлов цепи, $\varepsilon-$ энергия связи, $r_{0}-$ равновесная длина связи, $k>l$ (степень отталкивания $k$ всегда больше степени притяжения узлов $l$ ).

Шаг цепи $R_{0}$ находится как половина шага основного состояния плоской наноленты со структурой зигзаг. Параметр $K$, задающий продольную жесткость, и параметр $\epsilon$, задающий изгибную жесткость цепи, могут быть получены из анализа дисперсионных кривых наноленты. Параметры потенциала Леннарда-Джонса (4) могут быть либо напрямую вычислены как суммы невалентных взаимодействий одного атома с поперечной линией атомов наноленты, либо оценены из анализа структуры рулона наноленты, полученного с использованием полноатомной модели. Значения параметров цепной модели для нанолент графена $(\mathrm{CC})_{\infty}$, графана $(\mathrm{HCCH})_{\infty}$, фторографена $(\mathrm{FCCF})_{\infty}$ и фторографана $(\mathrm{HCCF})_{\infty}$ представлены в таблице.

При построении модели рассматриваются широкие наноленты, поэтому химическую модификацию ее краев можно не учитывать, а все параметры наноленты нужно нормировать на ее ширину. В этом случае масса одного звена цепи $M$ для наноленты графена будет равна массе двух атомов углерода $\left(M=2 M_{\mathrm{C}}=24 m_{p}\right)$, для наноленты графана $M=2\left(M_{\mathrm{C}}+M_{\mathrm{H}}\right)=26 m_{p}$ и фторографена $M=2\left(M_{\mathrm{C}}+M_{\mathrm{F}}\right)=62 m_{p}$, а для наноленты фторографана $M=2 M_{\mathrm{C}}+M_{\mathrm{H}}+M_{\mathrm{F}}=44 m_{p}$, где $m_{p}-$ масса протона.

Параметры продольной и изгибной жесткости цепи $K$ и $\epsilon$ для графена получены в [29,30]. При значениях $K=910 \mathrm{~N} / \mathrm{m}$ и $\epsilon=7 \mathrm{eV}$ дисперсионные кривые цепи наиболее точно совпадают с дисперсионными кривыми плоской наноленты графена соответствующими ее продольным и изгибным колебаниям. Значения $K$ и $\epsilon$ для других нанолент тоже могут быть получены из анализа дисперсионных кривых нанолент, полученных с использованием полноатомных моделей. Для анализа структуры и динамики нанолент графана, фторографена и фторографана были использованы силовые поля COMPASS [31] и CFF91.

Ван-дер-ваальсовы взаимодействия атомов в силовом поле COMPASS описываются потенциалом ЛеннардаДжонса (4) с показателями $l=6, k=9$. Возьмем наноленту графена и, используя этот потенциал, вычислим энергию взаимодействия двух связанных атомов углерода, расположенных на одной поперечной линии со всеми атомами углерода, расположенным на другой поперечной линии наноленты. Вычисления показывают, 


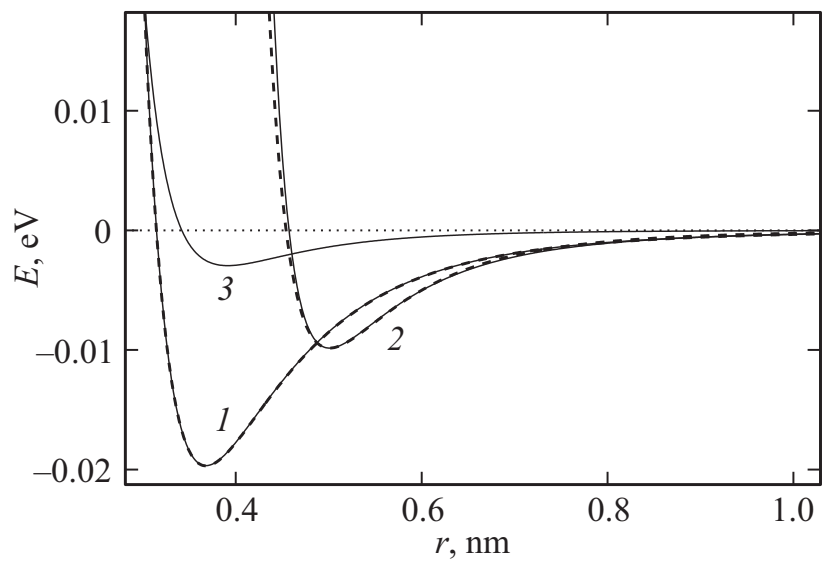

Рис. 4. Зависимость энергии $E$ взаимодействия двух разных поперечных линий атомов наноленты от расстояния между линиями $r$ для наноленты графена, графана и фторографена (кривые 1-3). Пунктирные кривые дают зависимости, вычисленные с использованием полноатомной модели широкой наноленты, сплошные линии дают зависимости соответствующие потенциалу Леннарда-Джонса (4) с параметрами $\varepsilon=0.0197 \mathrm{eV}, r_{0}=0.368 \mathrm{~nm}, l=5, k=8$ (кривая 1), $\varepsilon=0.00984 \mathrm{eV}, r_{0}=0.501 \mathrm{~nm}, l=6, k=16$ (кривая 2), $\varepsilon=0.00304 \mathrm{eV}, r_{0}=0.575 \mathrm{~nm}, l=9, k=20$ (кривая 3).

что зависимость этой энергии взаимодействия двух разных поперечных линий атомов от расстояния между линиями хорошо описывается потенциалом ЛеннардаДжонса (4) с показателями $l=5, k=8$ (рис. 4). Аналогичные вычисления энергии взаимодействия поперечных линий атомов можно провести и для нанолент графана (здесь нужно будет вычислить энергию взаимодействия группы связанных атомов $\mathrm{H}-\mathrm{C}-\mathrm{C}-\mathrm{H}$ одной поперечной линии со всеми атомами другой поперечной линии). Вычисления показывают, что энергию взаимодействия поперечных линий для графана тоже можно с хорошей точностью описать потенциалом (4) с показателями $l=6, k=16$.

Для нанолент фторографена и фторографана параметры потенциала межузельного взаимодействия (4) удобнее оценить из анализа структуры рулона наноленты, полученного в полноатомной модели.

\section{3. Стационарные состояния рулонных упаковок}

Для нахождения стационарного состояния рулонной упаковки наноленты нужно решить задачу на минимум

$$
E_{\text {total }} \rightarrow \min ,
$$

т.е. минимизировать потенциальную энергию полноатомной модели наноленты по всем координатам ее атомов, стартуя с начальной рулоноподобной конфигурации (минимизация проводилась численно с использованием метода сопряженных градиентов).
При использовании цепной модели для нахождения рулонной структуры нужно решить задачу на минимум

$$
\begin{aligned}
E= & \sum_{n=1}^{N-1} V\left(R_{n}\right)+\sum_{n=2}^{N-1} U\left(\theta_{n}\right) \\
& +\sum_{n=1}^{N-3} \sum_{k=n+3}^{N} W\left(r_{n k}\right) \rightarrow \min :\left\{\mathbf{u}_{n}\right\}_{n=1}^{N},
\end{aligned}
$$

где $N$ - число звеньев цепи [длина наноленты $\left.L=(N-1) R_{0}\right]$.

Задача (6) решалась численно с использованием метода сопряженных градиентов. Для проверки устойчивости полученной стационарной конфигурации $\left\{\mathbf{u}_{n}^{0}\right\}_{n=1}^{N}$ находились собственные значения матрицы вторых производных размерности $2 N \times 2 N$

$$
B=\left(\left.\frac{\partial E}{\partial \mathbf{u}_{n} \partial \mathbf{u}_{k}}\right|_{\left\{\mathbf{u}_{m}^{0}\right\}_{m=1}^{N}}\right)_{n=1, k=1}^{N, N} .
$$

Стационарная конфигурация цепи будет устойчивой, только если все собственные значения симметричной матрицы $B$ неотрицательны: $\lambda_{i} \geq 0, \quad i=1,2, \ldots, 2 N$. Заметим, что для устойчивой конфигурации первые три собственных значения всегда равны нулю: $\lambda_{1}=\lambda_{2}=\lambda_{3}=0$. Этим собственным значениям соответствуют движения цепи в плоскости как твердого тела (сдвиг по двум координатам и поворот). Остальным положительным собственным значениям $\lambda_{i}>0$ соответствуют собственные колебания структуры с частотами $\omega_{i}=\sqrt{\lambda_{3+i} / M}, i=1, \ldots, 2 N-3$.

Структура стационарного состояния цепи определяется ее начальной конфигурацией, используемой при решении задачи на минимум (6). Меняя начальную конфигурацию можно получать различные устойчивые упаковки цепи. Линейная конфигурация цепи (плоская нанолента) всегда является устойчивой, если угол $\theta_{0}=180^{\circ}$. Наличие невалентных взаимодействий узлов цепи приводит к существованию на плоскости других, более выгодных по энергии, стационарных упаковок цепи. При большой длине наиболее выгодной по энергии будет спиральная упаковка цепи (рулонная упаковка наноленты).

Типичный вид рулонной упаковки наноленты и соответствующей ей спиральной упаковки двумерной цепи представлен на рис. 5. Как видно из рисунка, спиральная упаковка цепи практически совпадает с поперечным сечением рулона наноленты. Геометрия рулона (спирали) задается числом его витков $N_{c}$ и его внутренним и внешним радиусами $R_{1}$ и $R_{2}$.

Рулонной упаковке наноленты соответствует расположение цепи в форме спирали Архимеда с внутренней полостью. Центр спирали удобно определить как центр ее тяжести $\mathbf{u}_{0}=\left(x_{0}, y_{0}\right)=\sum_{n=1}^{N} \mathbf{u}_{n}^{0} / N$, где двумерный вектор $\mathbf{u}_{n}^{0}=\left(x_{n}^{0}, y_{n}^{0}\right)$ задает положение звеньев цепи в 

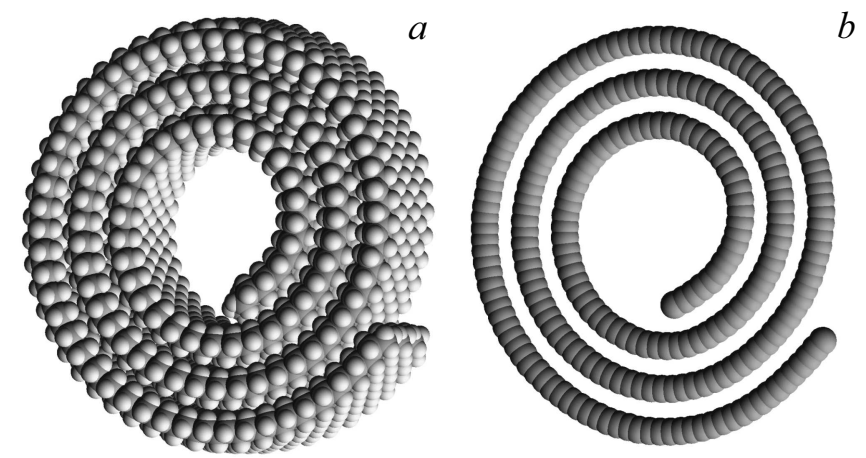

Рис. 5. Рулонная упаковка (a) наноленты графана $\left(\mathrm{C}_{12} \mathrm{H}_{14}\right)_{124} \mathrm{C}_{10} \mathrm{H}_{22} \quad$ размера $31.484 \times 1.373 \mathrm{~nm}$ и (b) двумерная цепная модель (число звеньев цепи $N=250$, число витков рулона $N_{c}=3.12$, внутренний радиус рулона $R_{1}=1.102 \mathrm{~nm}$, внешний радиус $R_{2}=2.108 \mathrm{~nm}$ ).

стационарной спиральной конфигурации. В полярных координатах

$$
x_{n}^{0}=x_{0}+R_{n}^{0} \cos \left(\varphi_{n}^{0}\right), \quad y_{n}^{0}=y_{0}+R_{n}^{0} \sin \left(\varphi_{n}^{0}\right),
$$

где радиус $R_{n}^{0}=\left|\mathbf{u}_{\mathbf{n}}^{0}-\mathbf{u}_{\mathbf{0}}\right|$ и дискретный угол $\varphi_{n}^{0}$ монотонно растут с увеличением номера звена цепи $n=1,2, \ldots, N$. Спираль характеризуется числом витков $N_{c}=\left(\varphi_{n}^{0}-\varphi_{1}^{0}\right) / 2 \pi$, внутренним радиусом (радиусом по первому витку) $R_{1}=\sum_{n=1}^{n_{1}} R_{n}^{0} / n_{1}$, где $n_{1}-$ число звеньев цепи, участвующих в образовании первого витка спирали, и внешним радиусом (радиусом по последнему витку) $R_{2}=\sum_{n=N-n_{2}+1}^{N} R_{n}^{0} / n_{2}$, где $n_{2}-$ число звеньев, участвующих в образовании последнего витка спирали. Для описания стационарного состояния рулонной упаковки удобно также определить целую часть числа витков $n_{c}=\left[N_{c}\right]+1$, где $[x]$ - целая часть числа $x$.

Жесткость спиральной конфигурации цепи характеризуется частотой $\omega_{1}=\sqrt{\lambda_{4} / M}$. Эта частота соответствует периодическому колебанию цепи, при котором происходит скручивание и раскручивание спирали. В приближении упругого стержня такое колебание было рассмотрено в работах $[16,27]$.

\section{4. Рулонные упаковки нанолент графана}

Структура рулонных упаковок нанолент графена была рассмотрена в работах $[29,30]$. Предложенная здесь более простая модель приводит к тем же самым результатам, поэтому рассмотрим только рулонные упаковки нанолент графана, фторографена и фторографана.

Опишем сначала возможные стационарные структуры нанолент графана. Для этого рассмотрим зависимость числа витков $N_{c}$, внутреннего $R_{1}$ и внешнего радиуса $R_{2}$ и наименьшей собственной частоты $\omega_{1}$ от длины рулона $L=(N-1) R_{0}$ (рис. 6,7$)$.
Характерный вид упаковок для нанолент разной длины представлен на рис. 8. Одновитковая конфигурация (число витков $n_{c}=1$ ) рулона (рис. $8, a$ ) может существовать только для нанолент длины $L \in[5.04,7.66] \mathrm{nm}$ (при числе звеньев $41 \leq N \leq 62$ ). Двухвитковая конфигурация $\left(n_{c}=2\right)$ рулона (рис. $\left.8, b\right)$ устойчива при длинах $L \in[6.05,18.79] \mathrm{nm} \quad(49 \leq N \leq 150)$. Для нанолент длины $L \in[16.77,33.92] \mathrm{nm} \quad(134 \leq N \leq 270)$ устойчивыми становятся структуры рулонов с тремя витками (рис. 8, $c, n_{c}=3$ ), при $L \in[31.40,50.31] \mathrm{nm}$ $(250 \leq N \leq 400)$ - структуры с четырьмя витками
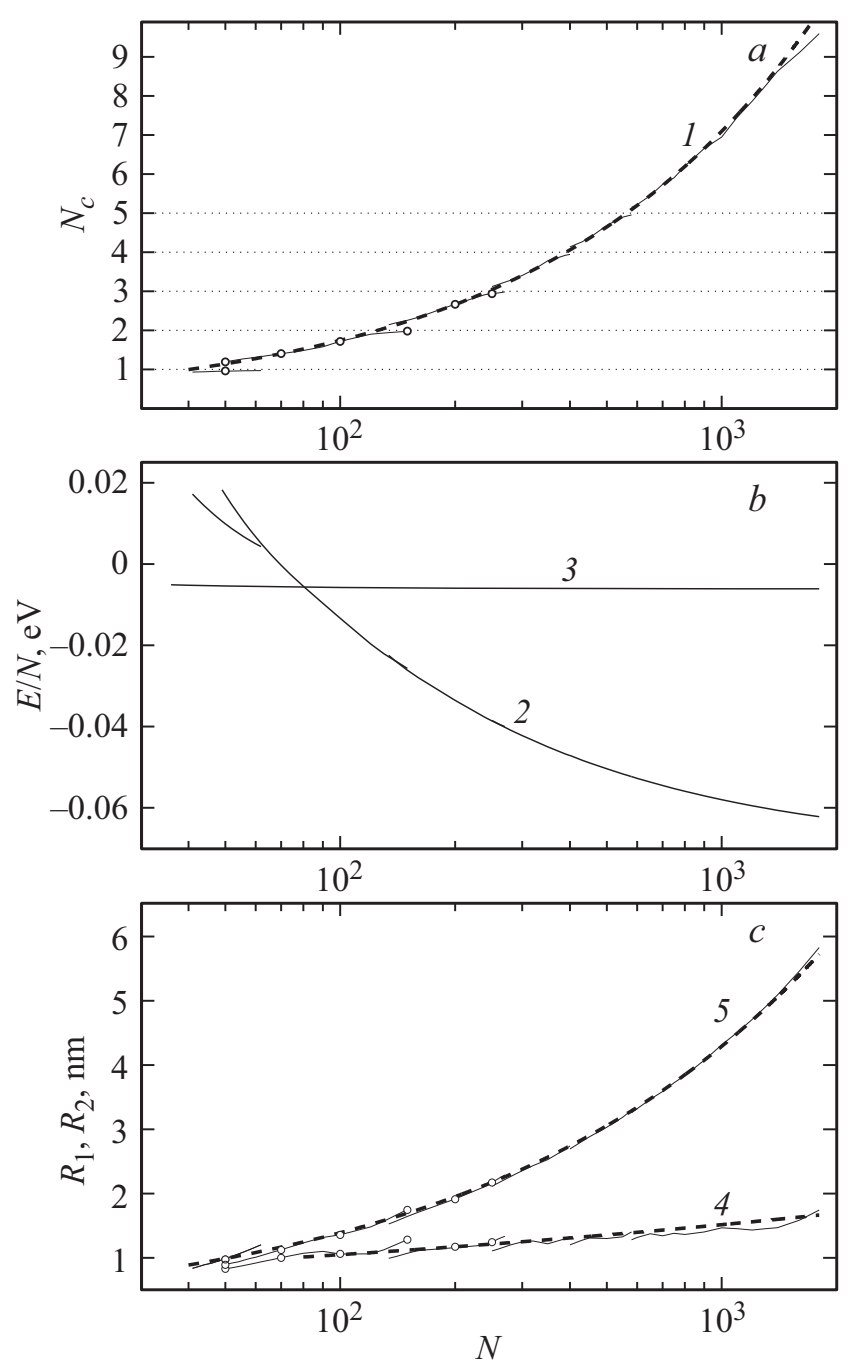

Рис. 6. Зависимости $(a)$ числа витков рулона $N_{c}$ наноленты графана; (b) удельной энергии структуры $E / N$ для рулонной упаковки и плоской структуры наноленты (кривые 2,3); внутреннего $R_{1}$ и внешнего радиуса $R_{2}$ рулонной упаковки наноленты (кривые 4,5 ) от числа ее звеньев $N$ (длина наноленты $L=(N-1) R_{0}$, продольный шаг $\left.R_{0}=0.1261 \mathrm{~nm}\right)$. Маркеры дают значения, полученные $\mathrm{c}$ использованием полноатомной модели наноленты $\left(\mathrm{C}_{12} \mathrm{H}_{14}\right)_{N / 2-1} \mathrm{C}_{10} \mathrm{H}_{22}$ ширины $D=1.373 \mathrm{~nm}$. Пунктирные линии дают степенные зависимости $N_{c}=0.105 N^{0.61}$ (кривая 1$), R_{1}=0.5 N^{0.16}$ и $R_{2}=0.145 N^{0.49} \mathrm{~nm}$ (кривые 4,5). 


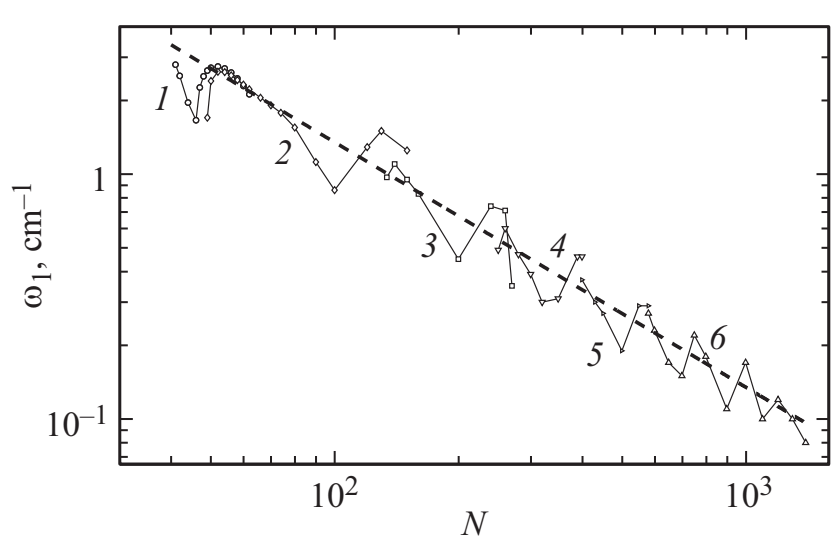

Рис. 7. Зависимость наименьшей частоты собственных колебаний рулона $\omega_{1}$ от числа звеньев наноленты графана $N$. Кривые $1,2, \ldots, 5$ и 6 дают зависимости для рулонных упаковок наноленты с $1,2, \ldots, 5$ и с 6 и более числами витков. Пунктирная линия дает зависимость $\omega_{1}=135 / \mathrm{N} \mathrm{cm}^{-1}$.

(рис. $\left.8, d, n_{c}=4\right)$, а при $L \geq 50.31 \mathrm{~nm}(N \geq 400)-$ структуры с пятью и более витками (рис. $8, e, f$ ).

При определенных длинах наноленты могут существовать две устойчивые конфигурации ее рулонной упаковки (рис. $8, c, d$ ). Эта бистабильность обусловлена невалентным взаимодействием концов нанолент. В одной конфигурации концы взаимодействуют более сильно (находятся ближе друг к другу), в другой - более слабо (концы более удалены друг от друга). Такая бистабильность имеет место и для рулонов нанолент графена [30]. Поэтому зависимости $N_{c}, R_{1}, R_{2}, \omega_{1}$ от длины $L$ (от числа звеньев цепи $N$ ) разделяются на ветви соответствующие конфигурациям рулонной упаковки с одинаковым числом витков $n_{c}$ (рис. 6,7 ).

Как видно из рис. 6, увеличение длины наноленты приводит к монотонному росту витков ее рулонной упаковки согласно степенному закону $N_{c} \approx 0.105 N^{0.61}$ для $N \rightarrow \infty$. С увеличением длины по степенному закону растет также радиус внутренней полости $R_{1} \approx 0.5 N^{0.16}$ и внешний радиус рулона $R_{2} \approx 0.145 N^{0.49} \mathrm{~nm}$. Удельная энергия спирали (рулона) $E / N$ монотонно уменьшается с увеличением числа звеньев (чем длиннее нанолента, тем большее энергетический выигрыш от ее сборки в рулон). При малых длинах $L<10.1 \mathrm{~nm}$ плоская форма наноленты является самой выгодной по энергии, а при длинах $L \geq 10.1 \mathrm{~nm}$ более выгодной становиться рулонная упаковка.

Наименьшая собственная частота рулона $\omega_{1}$ соответствует колебанию, при котором происходит его периодическое скручивание и раскручивание (узлы модельной цепи при этом двигаются строго по спирали Архимеда). Увеличение длины рулона приводит к уменьшению частоты этого колебания $\omega_{1} \approx 135 / N \mathrm{~cm}^{-1}$ для $N \rightarrow \infty$ (рис. 7). По аналогичному закону уменьшается наименьшая собственная частота рулонной упаковки наноленты графена $[16,27,30]$.

Для проверки результатов, полученных с помощью цепной модели, были также найдены с использованием полноатомной модели стационарные рулонные упаковки нанолент графана различной длины. При ширине $D=1.373 \mathrm{~nm}$ наноленту графана соответствующую цепи из $N$ звеньев можно описать формулой $\left(\mathrm{C}_{12} \mathrm{H}_{14}\right)_{N / 2-1} \mathrm{C}_{10} \mathrm{H}_{22}$ (рис. $\left.1, b\right)$. Как видно из рис. 6, полноатомная модель приводит к тем же самым значениям числа витков $N_{c}$ и радиусам рулона $R_{1}, R_{2}$, что и двумерная цепная модель. Таким образом, цепная модель для нанолент графана позволяет с большой точностью находить их рулонные упаковки.

\section{5. Рулонные упаковки нанолент фторографена}

Нанолента фторографена отличается от наноленты графана тем, что у нее вместо атомов водорода к атомам

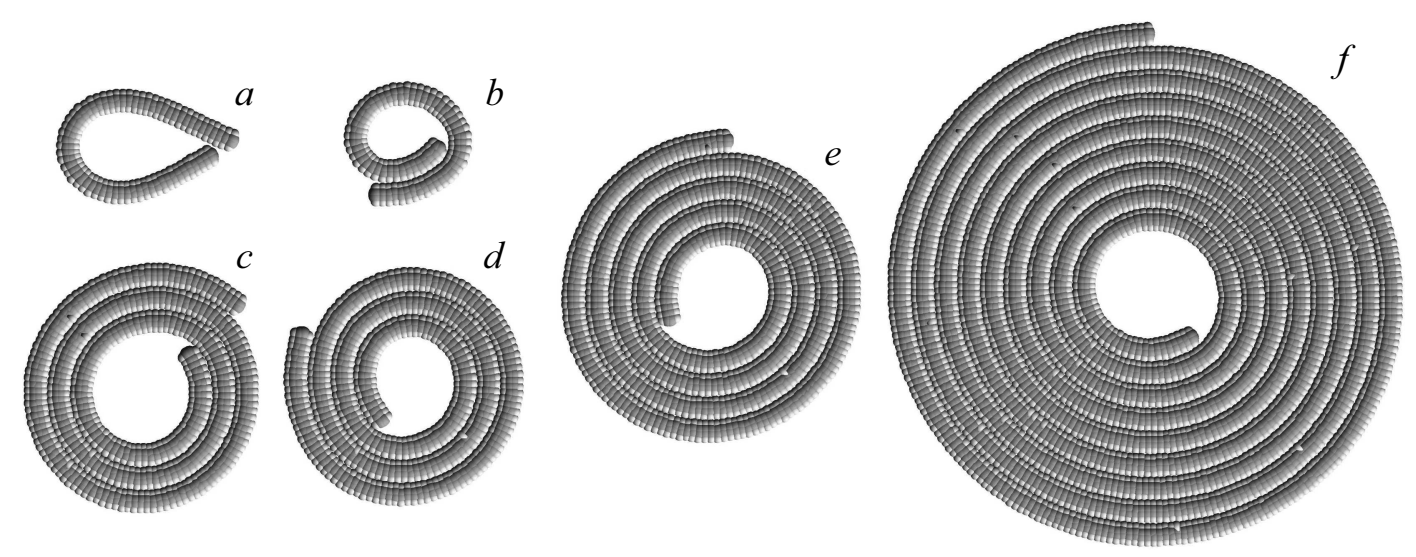

Рис. 8. Рулонные упаковки нанолент графана при числе звеньев $(a) N=62$ (число витков рулона $N_{c}=0.97$, внутренний и внешний радиус рулона $\left.R_{1}=R_{2}=1.198 \mathrm{~nm}\right) ;(b) N=62\left(N_{c}=1.33, R_{1}=0.933, R_{2}=1.029 \mathrm{~nm}\right) ;(c) N=270\left(N_{c}=2.99, R_{1}=1.331\right.$, $\left.R_{2}=2.282 \mathrm{~nm}\right) ;(d) N=270\left(N_{c}=3.23, R_{1}=1.168, R_{2}=2.210 \mathrm{~nm}\right) ;(e) N=450\left(N_{c}=4.37, R_{1}=1.303, R_{2}=2.874 \mathrm{~nm}\right)$ и (f) $N=1400\left(N_{c}=8.6, R_{1}=1.464, R_{2}=5.074 \mathrm{~nm}\right)$. 

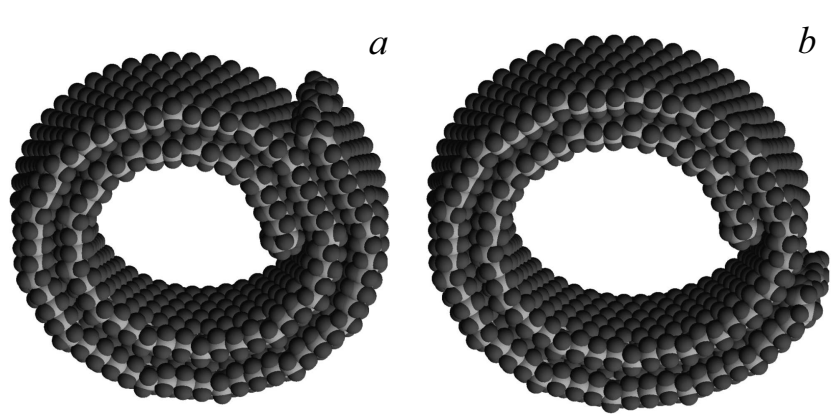

Рис. 9. Рулонные упаковки нанолент фторографена $\left(\mathrm{C}_{12} \mathrm{~F}_{14}\right)_{99} \mathrm{C}_{10} \mathrm{~F}_{22}$ размера $25.631 \times 1.421 \mathrm{~nm}$ (число звеньев $N=200)$ с $(a)$ числом витков $N_{c}=2.16$ (внутренний радиус $R_{1}=1.574$, внешний радиус рулона $\left.R_{2}=2.210 \mathrm{~nm}\right)$ и $(b)$ с $N_{c}=1.94\left(R_{1}=1.821, R_{2}=2.349 \mathrm{~nm}\right)$.

углерода присоединены атомы фтора. Атом фтора значительно крупнее атома водорода, а валентная связь $\mathrm{C}-\mathrm{F}$ более сильно поляризована, чем связь $\mathrm{C}-\mathrm{H}$ (в силовом поле COMPASS [31] считается, что на атомах связи $\mathrm{C}-\mathrm{F}$ находятся заряды $q_{\mathrm{C}}=0.25 e, q_{\mathrm{F}}=-0.25 e$, а на атомах связи $\mathrm{C}-\mathrm{H}-$ заряды $q_{\mathrm{C}}=-0.053 e, q_{\mathrm{H}}=0.053 e$, где $e$ - заряд электрона). Кулоновское отталкивание отрицательно заряженных атомов фтора приводит к значительному ослаблению взаимодействия соприкасающимися участков наноленты. Анализ полноатомной модели ноноленты показывает, что соприкасающиеся участки наноленты все равно продолжают притягиваться друг к другу, а наноленты могут образовывать устойчивые рулонные структуры (рис. 9). Отметим, что возможность существования рулонов нанолент фторографена получена впервые.

Большие размеры атомов фтора и сильная поляризация валентных связей $\mathrm{C}-\mathrm{F}$ затрудняет прямое вычисление потенциала междоузельного взаимодействия $W(r)$ для цепной модели. Показатели $k$ и $l$ потенциала (4) можно оценить из асимптотик энергии взаимодействия участков наноленты при их сближении и удалении друг от друга. Параметры $r_{0}$ и $\varepsilon$ здесь были выбраны так, чтобы структура рулонов полученных с использованием полноатомной модели наилучшим образом совпадала со структурой спиральных упаковок цепи, полученных с использованием цепной модели. Наилучшее совпадение достигается при использовании значений параметров данных в таблице.

Зависимость числа витков $N_{c}$, внутреннего $R_{1}$ и внешнего радиуса $R_{2}$ рулона от длины наноленты фторографена $L=(N-1) R_{0}$ дана на рис. 10 . Для нанолент фторографена существуют только двух- и более витковые рулонные упаковки (всегда число витков $N_{c}>1$ ). Двухвитковая конфигурация $\left(n_{c}=2\right)$ может существовать только для нанолент длины $L \in[8.61,29.4] \mathrm{nm}$ (при числе звеньев $68 \leq N \leq 230$ ). Для нанолент длины $L \in[25.57,512.72] \mathrm{nm}(200 \leq N \leq 400)$ устойчивыми становятся структуры рулона с тремя витками, а при $L \geq 512.72 \mathrm{~nm}$ - структуры с четырьмя и более витками.

При определенных длинах могут одновременно существовать две устойчивые конфигурации рулонной упаковки наноленты (рис. 9). Эта бистабильность также как и для нанолент графана обусловлена невалентным взаимодействием концов наноленты. В силу нее зависимости $N_{c}, R_{1}$ и $R_{2}$ от длины $L$ (от числа звеньев $N$ ) разделяются на ветви соответствующие конфигурациям рулонной упаковки с одинаковым числом витков $n_{c}$ (рис. 10).

Как видно из рис. 10, увеличение длины наноленты приводит к монотонному росту витков ее рулонной

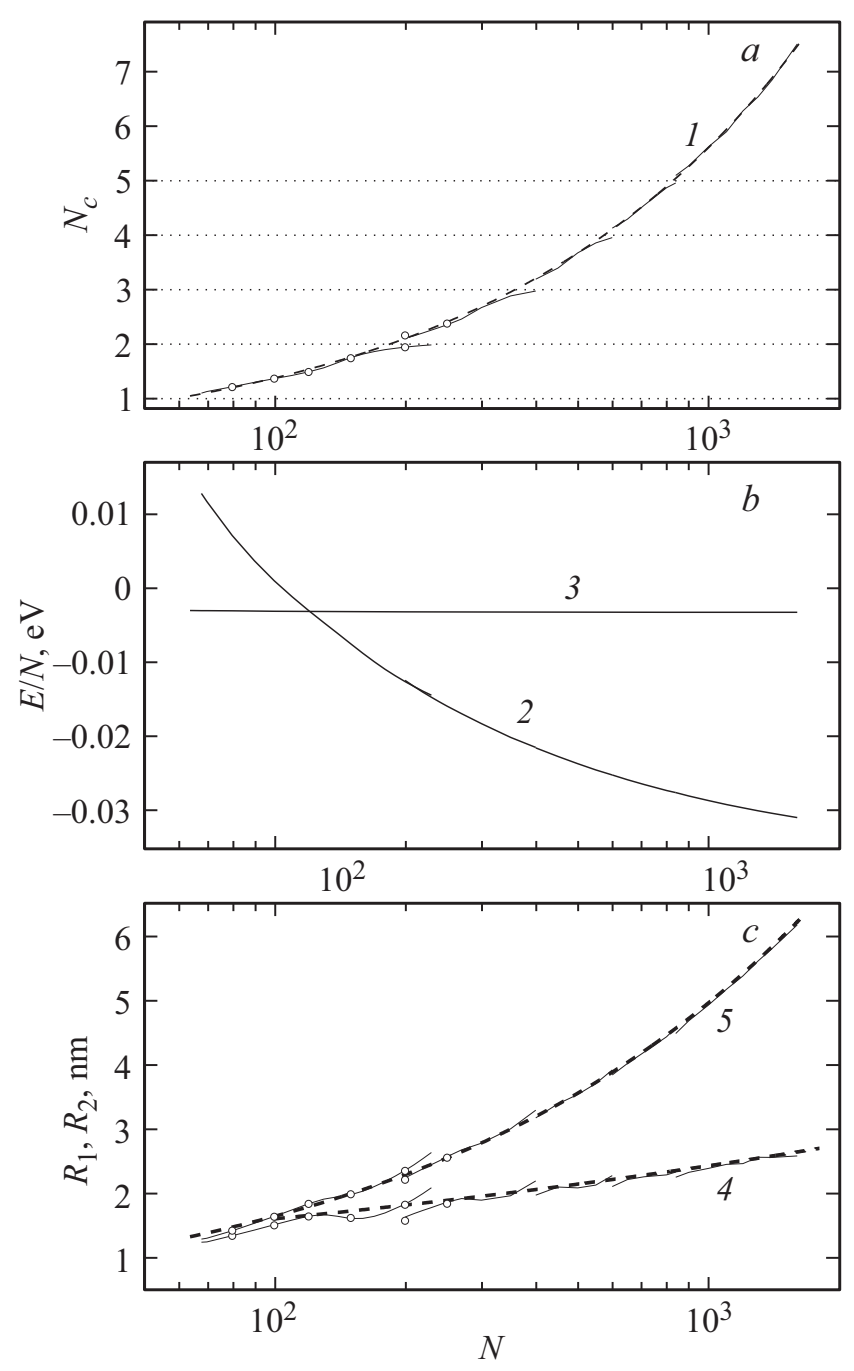

Рис. 10. Зависимости $(a)$ числа витков рулона $N_{c}$ наноленты фторографана; $(b)$ удельной энергии структуры $E / N$ для рулонной упаковки и плоской структуры наноленты (кривые 2,3); внутреннего $R_{1}$ и внешнего радиуса $R_{2}$ рулонной упаковки наноленты (кривые 4,5 ) от числа ее звеньев $N$ (длина наноленты $L=(N-1) R_{0}$, продольный шаг $\left.R_{0}=0.1285 \mathrm{~nm}\right)$. Маркеры дают значения, полученные с использованием полноатомной модели наноленты $\left(\mathrm{C}_{12} \mathrm{~F}_{14}\right)_{N / 2-1} \mathrm{C}_{10} \mathrm{~F}_{22}$ шириной $D=1.421 \mathrm{~nm}$. Пунктирные линии дают степенные зависимости $N_{c}=0.083 N^{0.61}$ (кривая 1), $R_{1}=0.7 N^{0.18}, R_{2}=0.18 N^{0.48} \mathrm{~nm}$ (кривые 4, 5). 

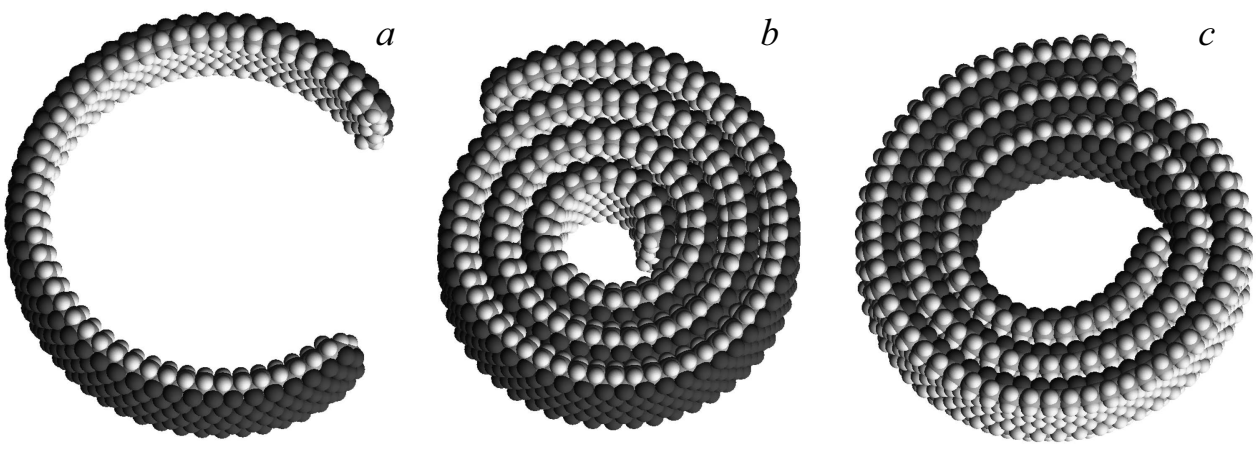

Рис. 11. Основное состояние $(a)$ наноленты фторографана $\left(\mathrm{C}_{12} \mathrm{H}_{8} \mathrm{~F}_{6}\right)_{47} \mathrm{C}_{10} \mathrm{H}_{17} \mathrm{~F}_{5}$ (ширина ленты $D=1.417 \mathrm{~nm}$, число звеньев $N=96)$. Наиболее $(b)$ и наименее $(c)$ энергетически выгодная рулонная упаковка наноленты $\left(\mathrm{C}_{12} \mathrm{H}_{8} \mathrm{~F}_{6}\right)_{127} \mathrm{C}_{10} \mathrm{H}_{17} \mathrm{~F}_{5}(N=256)$ : упаковка с фторированной внешней поверхностью (число витков рулона $N_{c}=3.43$, радиусы рулона $R_{1}=0.911, R_{2}=2.180 \mathrm{~nm}$ ) и упаковка с фторированной внутренней поверхностью $\left(N_{c}=2.8, R_{1}=1.443, R_{2}=2.338 \mathrm{~nm}\right)$. Разница энергии между конформациями $(b)$ и $(c) \Delta E=29.7 \mathrm{eV}$.

упаковки согласно степенному закону $N_{c} \approx 0.083 N^{0.61}$ для $N \rightarrow \infty$. С увеличением длины по степенному закону растет также радиус внутренней полости $R_{1} \approx 0.7 N^{0.18}$ и внешний радиус рулона $R_{2} \approx 0.18 N^{0.48} \mathrm{~nm}$. Удельная энергия спирали (рулона) $E / N$ монотонно уменьшается с увеличением числа звеньев - чем длиннее нанолента тем большее энергетический выигрыш от ее сборки в рулон. При малых длинах $L<15.4 \mathrm{~nm}$ плоская форма наноленты является самой выгодной по энергии, а при длинах $L \geq 15.4 \mathrm{~nm}$ более выгодной становится рулонная упаковка.

Для проверки результатов, полученных с помощью цепной модели, были также найдены с использованием полноатомной модели стационарные рулонные упаковки нанолент фторографена различной длины. При ширине $D=1.421 \mathrm{~nm}$ наноленту фторографена соответствующую цепи из $N$ звеньев можно описать формулой $\left(\mathrm{C}_{12} \mathrm{~F}_{14}\right)_{N / 2-1} \mathrm{C}_{10} \mathrm{~F}_{22}$ (рис. 1,c). Как видно из рис. 10 полноатомная модель дает хорошее совпадение числа витков $N_{c}$ и радиусов рулона $R_{1}, R_{2}$ со значениями полученными с помощью цепной модели. Таким образом, цепная модель для нанолент фторографена также позволяет с хорошей точностью находить их рулонные упаковки.

\section{6. Рулонные упаковки нанолент фторографана}

Рассмотрим наноленту фторографана, представленную на рис. $1, d$. Главной особенностью этой наноленты является неэквивалентность ее сторон. Одна ее сторона гидрированна (к атомам углерода присоединены атомы водорода), а другая - фторирована (к атомам углерода присоединены атомы фтора). Так как атомы фтора крупнее атомов водорода и имеют значительно больший электрический заряд, то они сильнее отталкиваются друг от друга. Поэтому плоская форма такой наноленты не является устойчивым состоянием. Нанолента всегда выгибается и образует выпуклую поверхность, на внешней стороне которой находятся атомы фтора, а на внутренней - атомы водорода. Если длина наноленты значительно превосходит ее ширину, то в основном состоянии она принимает форму дуги окружности (рис. 11,a). Образование дуги приводит к сближению концов наноленты, что может приводить к самосборке наноленты в рулонную структуру [32].

В цепной модели неэквивалентность сторон наноленты отражается в отличии равновесного значения валентного угла $\theta_{0}$ от $180^{\circ}$. Для наноленты фторографана угол $\theta_{0}=177^{\circ}$. Выпуклая нанолента может быть свернута в рулон двумя способами - в рулон, в котором его внешняя сторона совпадает с выпуклой стороной наноленты, и в рулон, в котором нет этого совпадения (выпуклая сторона наноленты является внутренней стороной рулона) (рис. 11, $b, c)$. Самой выгодной по энергии всегда будет первая форма рулона, так как в ней выпуклость наноленты совпадает с ее изгибом в рулоне. В цепной модели эти формы рулона будут соответствовать упаковкам цепи в спираль с разной хиральностью (правой и левой спирали).

Зависимость числа витков $N_{c}$ и внутреннего $R_{1}$ и внешнего радиуса $R_{2}$ рулона от длины наноленты (от числа звеньев цепи $N$ ) представлена на рис. 12. Как видно из рисунка, рулон наноленты с фторированной внешней поверхность всегда более выгоден по энергии и имеет более компактную форму, чем рулон с гидрированной внешней поверхностью. Число витков $N_{c} \approx 0.165 N^{0.56}$ для первой формы и $N_{c} \approx 0.135 N^{0.56}$ для второй формы рулона. Радиус внутренней полости рулона первой формы практически не зависит от ее длины $R_{1} \approx 0.84$, а внешний радиус $R_{2} \approx 0.11 N^{0.53} \mathrm{~nm}$. Для рулона второй формы $R_{1} \approx 0.38 N^{0.23}, R_{2} \approx 0.135 N^{0.51} \mathrm{~nm}$ для $N \rightarrow \infty$.

Заметим, что обе формы рулона, имеющие разную закрутку, являются устойчивыми конфигурациями. Наиболее энергетически выгодную первую форму рулона 


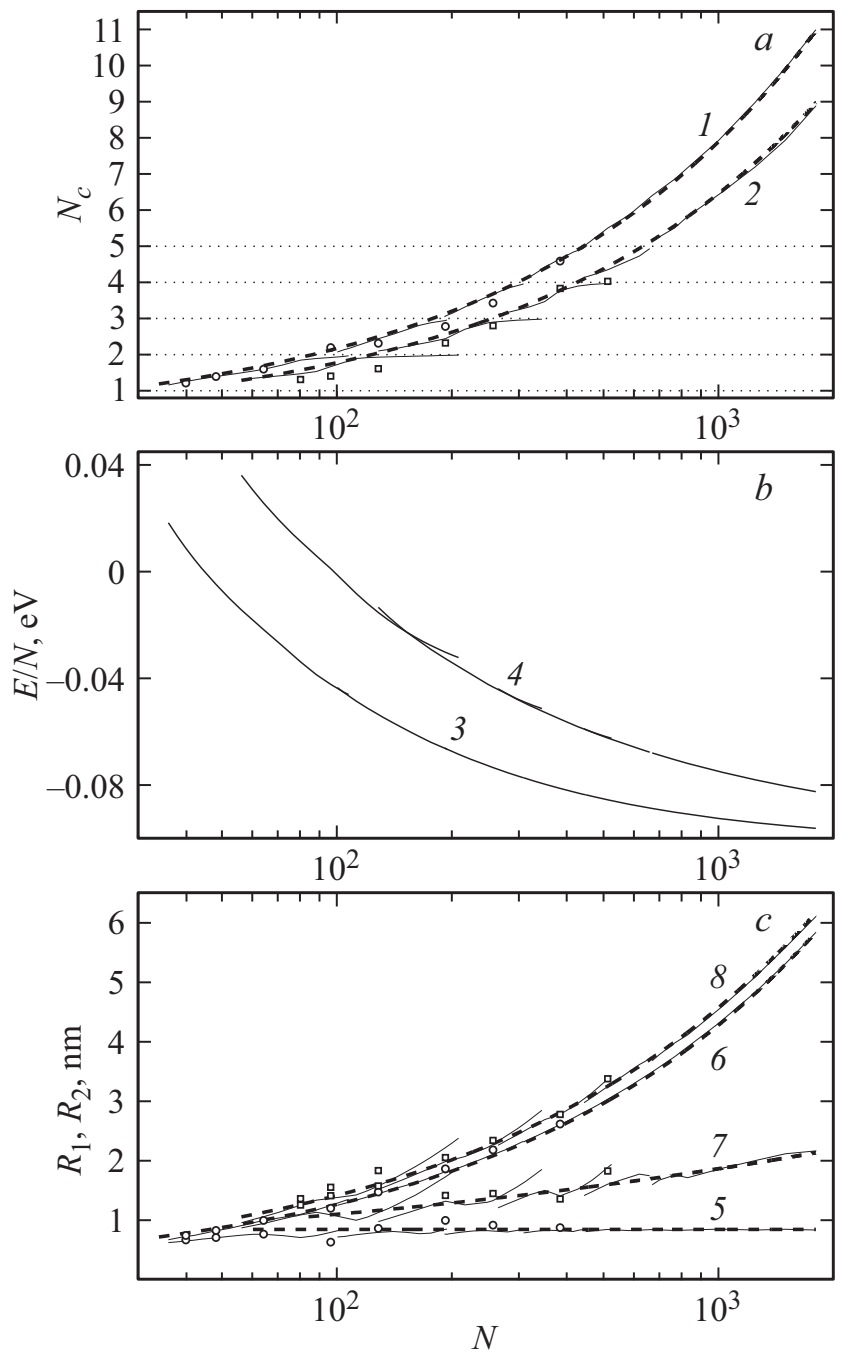

Рис. 12. Зависимости (a) числа витков рулона $N_{c}$ наноленты фторографана; $(b)$ удельной энергии рулонной структуры $E / N$; внутреннего $R_{1}$ и внешнего радиуса $R_{2}$ рулонной упаковки наноленты от числа ее звеньев $N$. Кривые $1,3,5$ и 6 дают зависимости для рулона с фторированной внешней поверхностью, кривые 2,4,7 и 8 - для рулона с фторированной внутренней поверхностью. Маркеры дают значения, полученные с использованием полноатомной модели наноленты $\left(\mathrm{C}_{12} \mathrm{H}_{8} \mathrm{~F}_{6}\right)_{N / 2-1} \mathrm{C}_{10} \mathrm{H}_{17} \mathrm{~F}_{5}$ ширины $D=1.394 \mathrm{~nm}$. Пунктирные линии дают степенные зависимости $N_{c}=0.165 N^{0.56}$ и $N_{c}=0.135 N^{0.56}$ (кривые 1 и 2), $R_{1}=0.84 N^{0}, R_{2}=0.11 N^{0.53} \mathrm{~nm}$ (кривые 5 и 6) и $R_{1}=0.38 N^{0.23}, R_{2}=0.135 N^{0.51} \mathrm{~nm}$ (кривые 7 и 8 ).

могут образовывать наноленты длины $L>4.50 \mathrm{~nm}$, а вторую - только наноленты длины $L>7.07 \mathrm{~nm}$.

Для проверки результатов, полученных с помощью цепной модели, были также найдены с использованием полноатомной модели стационарные рулонные упаковки нанолент фторографана различной длины. При ширине $D=1.421 \mathrm{~nm}$ наноленту фторографана, соответствующую цепи из $N$ звеньев, можно описать формулой $\left(\mathrm{C}_{12} \mathrm{H}_{8} \mathrm{~F}_{6}\right)_{N / 2-1} \mathrm{C}_{10} \mathrm{H}_{17} \mathrm{~F}_{5}$ (рис. $\left.1, d\right)$. Как видно из рис. 12 , двумерная цепная модель дает хорошее совпадение числа витков $N_{c}$ и радиусов рулона $R_{1}, R_{2}$ со значениями полученными с помощью полноатомной модели.

Таким образом, цепная модель для нанолент фторографана тоже позволяет с хорошей точностью находить их рулонные упаковки.

\section{7. Заключение}

В данной работе предложена наиболее упрощенная модель двумерной цепи, позволяющая точно и эффективно описывать рулонные конформации графеноподобных нанолент. Гамильтониан модели (1) учитывает продольную и изгибную жесткости наноленты, а также невалентные взаимодействия между поперечными слоями атомов наноленты. С использованием модели были получены возможные стационарные состояния рулонов однослойных нанолент графена, графана, фторографена и фторографана (гидрированного с одной стороны и фторированного с другой стороны графена). Найдена зависимость энергии, числа витков $N_{c}$ и внутреннего $R_{1}$ и внешнего радиуса $R_{2}$ рулона от длины наноленты. Показано, что при больших длинах рулонная упаковка является наиболее энергетически выгодной конформацией наноленты. Для нанолент фторографена впервые показана возможность существования рулонных упаковок, а для нанолент фторографана - существование двух разных типов рулонов, которые в цепной модели соответствуют левым и правым спиралям Архимеда.

Для проверки полученных с помощью цепной модели результатов были также найдены с использованием полноатомных моделей рулонные упаковки нанолент графана, фторографена и фторографана различной длины. Показано, что для этих нанолент цепная модель позволяет с хорошей точностью находить их рулонные упаковки.

Простота предложенной модели позволяет рассматривать динамику рулонов молекулярных нанолент достаточно большой длины и на достаточно больших интервалах времени. Модель может быть применена как для описания рулонных упаковок молекулярных нанолент с одинаковыми поверхностями (нанолент нитрида бора, силицина, фосфорена, карбон-нитрида и др.), так и для нанолент, стороны которых имеют разную химическую модификацию (наноленты графона и их аналоги).

\section{Список литературы}

[1] K.S. Novoselov, A.K. Geim, S.V. Morozov, D. Jiang, Y. Zhang, S.V. Dubonos, I.V. Grigorieva, A.A. Firsov. Science 306, 666 (2004).

[2] A.K. Geim, K.S. Novoselov. Nat. Mater. 6, 183 (2007).

[3] C. Soldano, A. Mahmood, E.Dujardin. Carbon 48, 2127 (2010).

[4] J.A. Baimova, B. Liu, S.V. Dmitriev, N. Srikanth, K. Zhou, Phys. Chem. Chem. Phys. 16, 19505 (2014). 
[5] J.A. Baimova, E.A. Korznikova, S.V. Dmitriev, B. Liu, K. Zhou. Rev. Adv. Mater. Sci. 39, 69 (2014).

[6] W. Bollmann, J. Spreadborough. Nature, 186, 29 (1960).

[7] G. Cheng, I. Calizo, X. Liang, B.A. Sperling, A.C. JohnstonPeck, W. Li, J.E. Maslar, C.A. Richtera, A.R.H. Walker. Carbon 76, 257 (2014).

[8] H.Q. Zhou, C.Y. Qiu, H.C. Yang, F. Yu, M.J. Chen, L.J. Hu, Y.J. Guo, L.F. Sun. Chem. Phys. Lett. 501, 475 (2011).

[9] X. Chen, R.A. Boulos, J.F. Dobson, C.L. Raston. Nanoscale 5, 498 (2013).

[10] M.V. Savoskin, V.N. Mochalin, A.P. Yaroshenko, N.I. Lazareva, T.E. Konstantinova, I.V. Barsukov, I.G. Prokofiev. Carbon 45, 2797 (2007).

[11] X. Xie, L. Ju, X. Feng, Y. Sun, R. Zhou, K. Liu, S. Fan, Q. Li, K. Jiang. Nano Lett. 9, 2565 (2009).

[12] A.L. Chuvilin, V.L. Kuznetsov, A.N. Obraztsov. Carbon 47, 3099 (2009).

[13] H. Pan, Y. Feng, J. Lin. Phys. Rev. B 72, 085415 (2005).

[14] R. Rurali, V.R. Coluci, D.S. Galvao. Phys. Rev. B 74, 085414 (2006).

[15] Y. Chen, J. Lu, Z. Gao. J. Phys. Chem. C 111, 1625 (2007).

[16] X. Shi, N.M. Pugno, Y. Cheng, H. Gao. J. Appl. Phys. 95, 163113 (2009).

[17] B.V.C. Martins, D.S. Galvao. Nanotechnology 21, 075710 (2010).

[18] S. Huang, B. Wang, M. Feng, X. Xu, X. Cao, Y. Wang. Surf. Sci. 634, 3 (2015).

[19] E. Perim, R. Paupitz, D.S. Galvao. J. Appl. Phys. 113, 054306 (2013).

[20] Y. Wang, H.F. Zhan, C. Yang, Y. Xiang, Y.Y. Zhang. Comp. Mater. Sci. 96300 (2015).

[21] X. Shi, Y. Cheng, N.M. Pugno, H. Gao. J. Appl. Phys. 96, 053115 (2010).

[22] Z. Zhang, T. Li. Appl. Phys. Lett. 97, 081909 (2010).

[23] L. Chu, Q. Xue, T. Zhang, C. Ling. J. Phys. Chem. C 115, 15217 (2011).

[24] N. Patra, Y. Song, P. Kral. ACS Nano 5, 1798 (2011).

[25] H.Y. Song, S.F. Geng, M.R. An, X.W. Zha. J. Appl. Phys. 113, 164305 (2013).

[26] Q. Yin, X. Shi. Nanoscale 5, 5450 (2013).

[27] X. Shi, N.M. Pugno, H. Gao. Acta Mech. Solida Sin. 23, 484 (2010).

[28] X. Shi, N.M. Pugno, H. Gao. Int. J. Fract. 171, 163 (2011).

[29] A.V. Savin, E.A. Korznikova, S.V. Dmitriev. PRB 92, 035412 (2015).

[30] А.В. Савин, Е.А. Корзникова, С.В. Дмитриев. ФТТ 57, 11, 2278 (2015).

[31] H. Sun. J. Phys. Chem. B 102, 7338 (1998).

[32] Y. Jin, Q. Xue, L. Zhu, X. Li, X. Pan, J. Zhang, W. Xing, T. Wu, Z. Liu. Scientific RepoRts 6, 26914 (2016). 